\title{
Vitamin C deficiency mimicking inflammatory bone disease of the hand
}

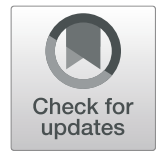

Emily J. Liebling ${ }^{1 *}$, Raymond W. Sze ${ }^{2,3}$ and Edward M. Behrens ${ }^{1,3}$

\begin{abstract}
Background: Severe vitamin C deficiency, or scurvy, encompasses a syndrome of multisystem abnormalities due to defective collagen synthesis and antioxidative functions. Among the more common presentations is a combination of oral or subcutaneous hemorrhage with lower extremity pain, the latter often exhibiting inflammatory bone changes on magnetic resonance imaging (MRI).

Case presentation: A 12-year-old male with anorexia nervosa presented with asymmetric painful swelling of multiple fingers of both hands. Imaging demonstrated soft tissue and bone marrow edema of several phalanges, without arthritis, concerning for an inflammatory process. Extensive imaging and laboratory evaluations were largely unrevealing, with the exception of a severely low vitamin C level and a moderately low vitamin D level. A diagnosis of scurvy was made and supplementation was initiated. Within 3 weeks of treatment, serum levels of both vitamins normalized and the digital abnormalities resolved on physical exam.

Conclusions: This represents the first description of scurvy manifesting with bone and soft tissue changes limited to the hands. There must be a high index of suspicion for scurvy in children with restricted dietary intake or malabsorption who have bone pain, irrespective of location of the lesions.
\end{abstract}

Keywords: Vitamin C deficiency, Inflammatory bone disease, Hand lesions

\section{Background}

Scurvy, the clinical syndrome of vitamin $\mathrm{C}$ deficiency, has long been considered a disease of the past, limited to sailors and other individuals with little access to ascorbic acid-containing fruits and vegetables. While rare in the modern era, severe vitamin $\mathrm{C}$ deficiency continues to occasionally occur, and has been particularly reported in children with neurodevelopmental restrictive eating habits [1]. Vitamin $C$ is an essential nutrient that has many functions, among which are its roles in collagen synthesis and multisystem antioxidative processes [2]. Low levels can, therefore, manifest as a pleiomorphic syndrome affecting the skin and hair, oral mucosa, musculoskeletal system, central nervous system, and bone marrow.

\footnotetext{
* Correspondence: lieblinge@email.chop.edu

'Division of Rheumatology, The Children's Hospital of Philadelphia, 3401 Civic Center Blvd, Philadelphia, PA 19104, USA

Full list of author information is available at the end of the article
}

Published case reports of vitamin C deficiency describe children who present with leg pain and refusal to bear weight $[3,4]$. Many have magnetic resonance imaging (MRI) findings of bilateral and symmetric bone marrow edema with periosteal and soft tissue signal abnormalities that are suspicious for infectious osteomyelitis, noninfectious osteomyelitis, or malignancy [5]. Here we describe a unique case of bone and soft tissue change secondary to vitamin $\mathrm{C}$ deficiency, which did not present with the classical pattern of lower extremity symptoms, but rather with multifocal finger pain and swelling.

\section{Case presentation}

A 12-year-old boy with anorexia nervosa presented with subacute multifocal digital swelling. He had been diagnosed with an eating disorder about 4 months prior to symptom onset, requiring admission to the Adolescent Medicine service for malnutrition, orthostasis and

(c) The Author(s). 2020 Open Access This article is licensed under a Creative Commons Attribution 4.0 International License, which permits use, sharing, adaptation, distribution and reproduction in any medium or format, as long as you give appropriate credit to the original author(s) and the source, provide a link to the Creative Commons licence, and indicate if changes were made. The images or other third party material in this article are included in the article's Creative Commons licence, unless indicated otherwise in a credit line to the material. If material is not included in the article's Creative Commons licence and your intended use is not permitted by statutory regulation or exceeds the permitted use, you will need to obtain permission directly from the copyright holder. To view a copy of this licence, visit http://creativecommons.org/licenses/by/4.0/ The Creative Commons Public Domain Dedication waiver (http://creativecommons.org/publicdomain/zero/1.0/) applies to the data made available in this article, unless otherwise stated in a credit line to the data. 
bradycardia, which resolved with monitored feeding. Despite ongoing behavioral therapy following discharge, however, adequate intake with continued weight gain remained a challenge. Over the course of 6 weeks, he developed additive and persistent swelling of the right hand first and fourth digits, followed by the left fifth digit (Fig. 1). The swelling was painful and unresponsive to nonsteroidal antiinflammatory drugs, there was no fever, and he identified no preceding trauma or illness. Physical exam was notable for fusiform swelling limited to the phalanges, as the joints themselves did not exhibit any discrete effusions. Furthermore, the overlying skin was normal in appearance and texture, without petechiae or ecchymoses, and no other mucocutaneous changes were present elsewhere. Complete musculoskeletal exam was otherwise normal, without other areas of swelling or pain. The patient appeared generally cachectic and review of the growth curve revealed significant weight loss with concomitant stunted vertical growth over the previous 2 years, with a sustained body mass index below the first percentile for age. He had previously exhibited a normal fecal calprotectin and at the time of this presentation did not report any gastrointestinal abnormalities concerning for enterocolonic inflammation or malabsorption. He denied practicing restrictive eating behaviors, but his diet included few fruits and vegetables. He was then admitted for a comprehensive medical work up of this constellation of symptoms.

Hand radiographs showed marrow and cortical erosive change with periosteal reaction and overlying soft tissue swelling of the involved phalanges (Fig. 2). MRI of the right hand revealed signal abnormalities with surrounding soft tissue edema, but without arthritis, in these areas (Fig. 3). These findings prompted concern for chronic noninfectious osteomyelitis (CNO) or an alternate noninfectious inflammatory entity, such as Langerhans Cell Histiocytosis (LCH). Subsequent whole body imaging did not identify any other areas of involvement. The isolation of the lesions to the hands was felt to be atypical for $\mathrm{CNO}$ and $\mathrm{LCH}$, particularly without evidence of systemic inflammation to further suggest such diagnoses. Therefore, further evaluations for other etiologies of finger swelling with bony changes were pursued.

Laboratory data were significant for normal complete blood count, iron studies, erythrocyte sedimentation rate, $\mathrm{C}$-reactive protein, and urinalysis. Immunologic serologies were similarly negative, including antinuclear antibody, Rheumatoid Factor, Human Leukocyte Antigen-B27, Celiac antibodies, and Lyme antibodies. Thyroid stimulating hormone and free thyroxine were only very slightly increased and decreased, respectively, but primary hypothyroidism was not thought to be causative of the marked failure to thrive. Hepatic function was intact, with normal albumin level and coagulation studies, but low prealbumin of $18.6 \mathrm{mg} / \mathrm{dL}$ (reference range $20-26 \mathrm{mg} / \mathrm{dL}$ ) was suggestive of a nutritional deficit. Further investigation of vitamin and mineral status showed normal zinc, folate, and vitamin B6 levels. However, vitamin $\mathrm{C}$ was strikingly low at $5 \mu \mathrm{mol} / \mathrm{L}$ (reference range $23-114 \mu \mathrm{mol} /$ $\mathrm{L}$ ), as was vitamin $\mathrm{D} 25-\mathrm{OH}$ at $12.2 \mathrm{ng} / \mathrm{mL}$ (normal $>30$ $\mathrm{ng} / \mathrm{mL}$ ).

The diagnosis of scurvy was made on the basis of a severely low vitamin $C$ level. Although scurvy bone lesions are typically described in the lower extremities, since the analogous lesions were present in the hands this was thought to be consistent with vitamin $\mathrm{C}$ deficiency.
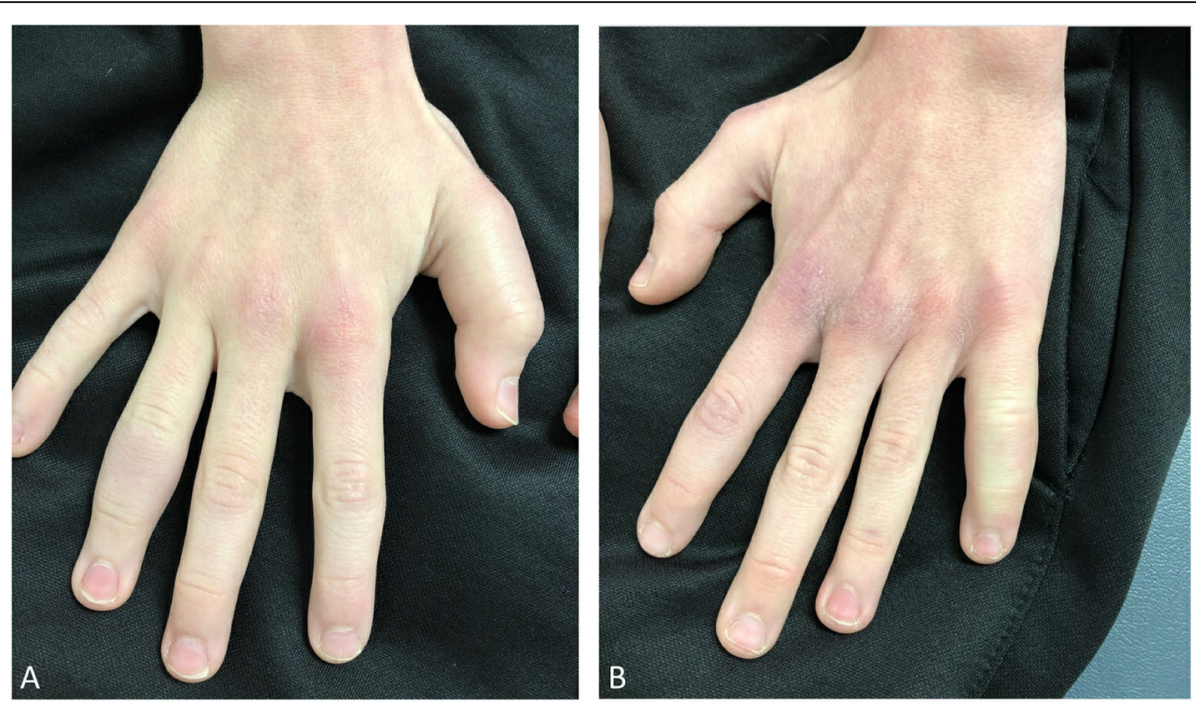

Fig. 1 a. Swelling of right first proximal phalanx and fourth middle phalanx. b. Swelling of left fifth middle phalanx 

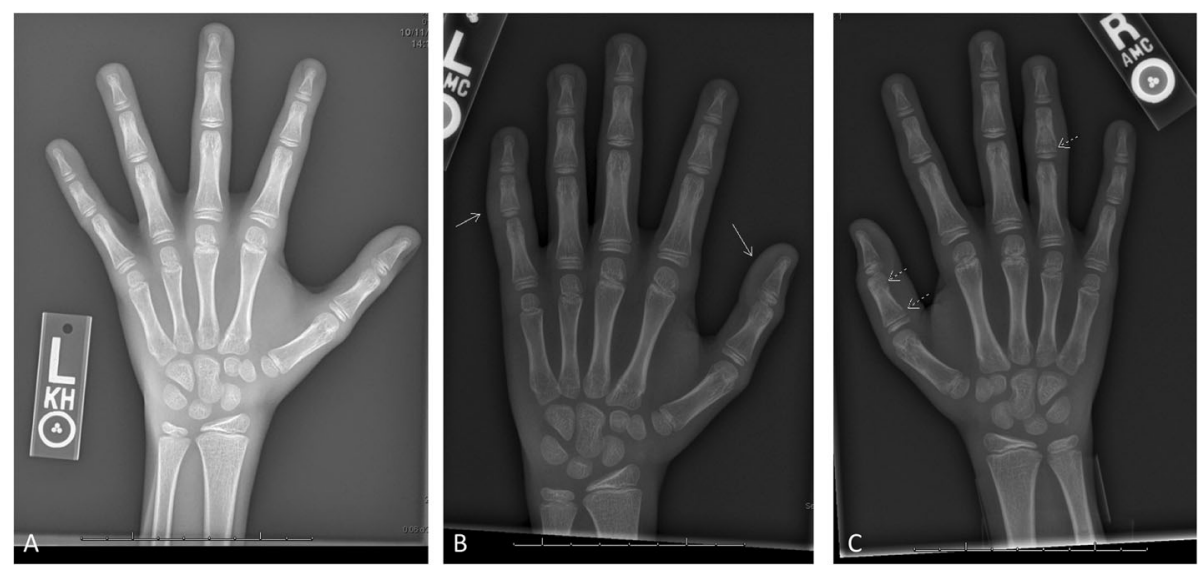

Fig. 2 a. Left hand radiograph taken 6 months prior shows delayed bone age, but no other abnormalities of the bones or soft tissues. Shown here for comparison. b. Left hand radiograph at presentation shows soft tissue swelling of the first and fifth digits (solid arrows). c. Right hand radiograph hand shows cortical erosion of the head of the first proximal phalanx and metaphyseal base of the fourth middle phalanx with periosteal reaction and overlying soft tissue swelling (dotted arrows)

These vitamin deficiencies were attributed to restricted intake due to anorexia nervosa, and treatment was initiated with ascorbic acid, cholecalciferol, and liquid meal supplements. The ascorbic acid regimen consisted of $100 \mathrm{mg} 3$ times per day orally for 7 days, followed by $100 \mathrm{mg}$ daily as maintenance; cholecalciferol dosing was $2000 \mathrm{U}$ orally daily. Within 3 weeks of starting therapy, vitamin levels normalized and the digital pain and swelling resolved.

\section{Discussion}

Humans are unable to produce ascorbic acid and, therefore, rely on exogenous intake to meet their physiologic needs. Its role as a cofactor in a variety of hydroxylation reactions makes vitamin $\mathrm{C}$ essential to processes such as collagen synthesis, hematopoiesis, angiogenesis, neural myelination, and iron and glucose metabolism [2, 6, 7]. Perhaps the most clinically well described consequences of deficiency are mucocutaneous hemorrhage, dermatitis,
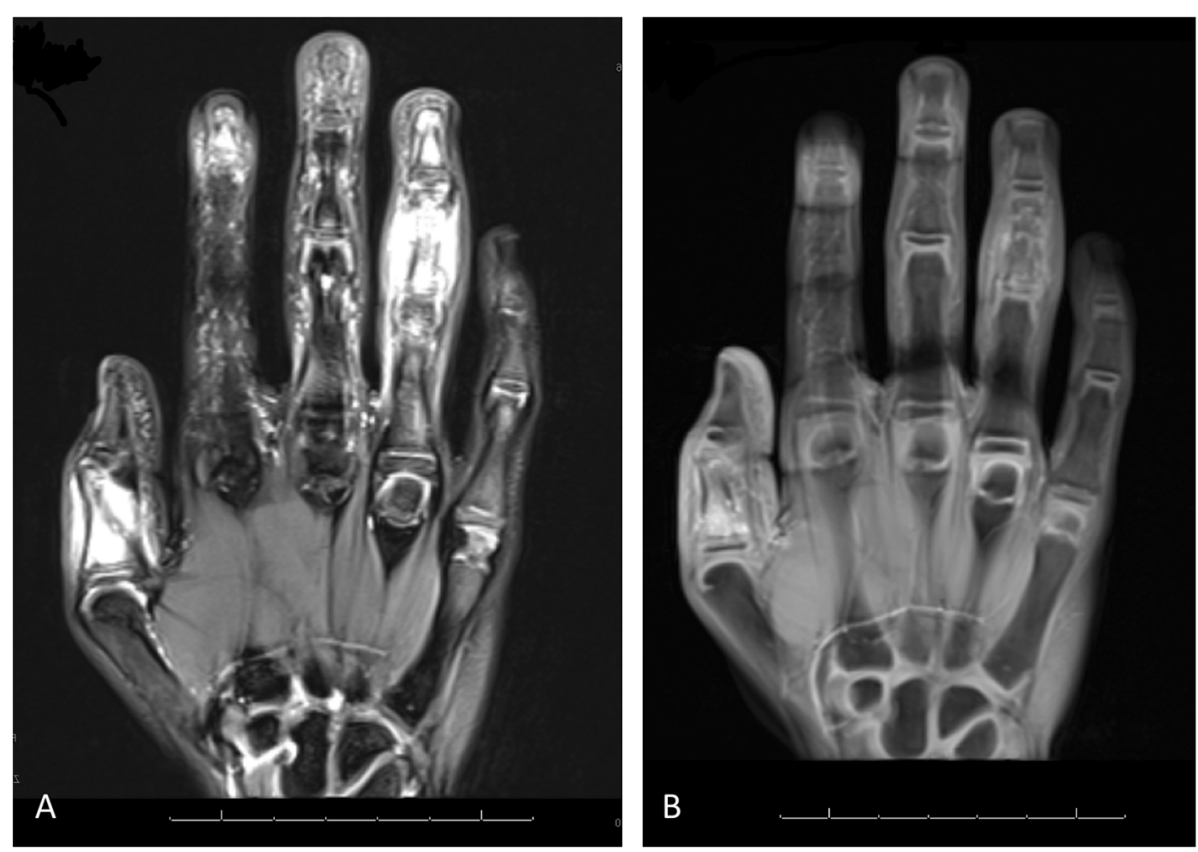

Fig. 3 Right hand MRI a. Coronal proton density fat saturation sequences of the right hand shows increased water signal involving multiple phalanges, but most prominently the first proximal phalanx and fourth middle phalanx. Abnormal marrow signal is associated with periosteal lifting and soft tissue edema. $\mathbf{b}$. Coronal $\mathrm{T} 1$ post-contrast with fat saturation shows contrast enhancement of the marrow space and soft tissue. Note the absence of joint effusions and synovial enhancement 
and bone pain. As mice are not dependent on dietary intake of vitamin $\mathrm{C}$, targeted gene deletion mouse models carrying defects in vitamin $C$ synthesis pathways serve as a system in which to study the scurvy syndrome; both human and murine scurvy symptoms correct with dietary repletion $[7,8]$.

The United States National Health and Nutrition Examination Survey data from 2003 to 2004 demonstrated that less than $4 \%$ of adolescents are vitamin C deficient [9]. The frequency of pediatric scurvy in published case series and individual reports suggests that neurodevelopmental disorders, such as autism spectrum disorder, are among the most common causes of restricted intake of vitamin C-containing foods [10]. Restricted intake secondary to eating disorders is known, as well, and was the cause of vitamin $\mathrm{C}$ deficiency in our adolescent male patient [11]. The bone pain described in most cases is typically diffuse in the lower extremities, with very young children refusing to ambulate, and imaging findings in corresponding locations. To our knowledge, this is the first report of scurvy bone disease manifesting exclusively in the hands.

Beyond a low serum vitamin $C$ level, skeletal imaging is an important component of the scurvy work up and diagnosis. The most suggestive features are often easier to identify on plain film rather than MRI, whose findings of marrow edema with abnormal periosteal and soft tissue signal can be fairly nonspecific and may prompt a broad work up for inflammatory conditions, infection, and metabolic disorders [5]. Our patient exhibited some of the classic scurvy $\mathrm{x}$-ray signs, which can include cortical thinning, erosions with joint space narrowing, periosteal reaction, and a "scorbutic zone" of a lucent metaphyseal band underlying a dense zone of provisional calcification [12,13]. With the exception of the scorbutic zone, these features can be present in inflammatory arthropathies, therefore, it is imperative to interpret imaging findings in the context of the larger clinical picture, which in this case was most suggestive of scurvy. The bone resorptive effects of vitamin $\mathrm{C}$ deficiency result from both impaired osteoblast function and increased osteoclast proliferation, the latter being a function of elevated Receptor Activator of Nuclear Factor- $\mathrm{kB}$ Ligand (RANKL) expression in bone marrow [14]. RANKL, a member of the Tumor Necrosis Factor (TNF) superfamily, promotes osteoclast differentiation, activity, and survival, and is implicated in the bone and joint destruction characteristic of rheumatoid arthritis [15]. This pathway suggests that abnormally low levels of ascorbic acid could invoke pathologic bone turnover that mimics inflammatory bone disease, thereby accounting for the MRI changes.

As our patient was not systemically inflamed or cytopenic, the concern for malignancy or infection was low, thus inflammatory and metabolic etiologies were pursued until the diagnosis was established on the basis of the abnormal vitamin $\mathrm{C}$ level, despite the absence of other classic scurvy stigmata, such as gingival bleeding or purpuric skin lesions. It was noted that the low vitamin D level may have contributed to the patient's symptoms, but there was not the typically associated osteopenia, nor would hypovitaminosis $\mathrm{D}$ alone have explained the soft tissue edema or periosteal reaction seen on MRI.

\section{Conclusions}

We report a case of scurvy in a patient with anorexia nervosa mimicking inflammatory bone disease of the hand, that improved with vitamin $C$ repletion. Most vitamin $C$ deficiency-related skeletal changes manifest in the lower extremities and, to our knowledge, this is the first description of such a syndrome presenting in the fingers. As exam and imaging findings are similar to inflammatory bone processes, such as osteomyelitis, there must be a high index of suspicion for scurvy in children who have bone pain in the setting of limited oral intake or impaired enteral absorption, irrespective of location of the lesions.

\section{Abbreviations \\ MRI: Magnetic resonance imaging; CNO: Chronic noninfectious osteomyelitis; LCH: Langerhans cell histiocytosis; RANKL: Receptor activator of nuclear factor-kB ligand; TNF: Tumor necrosis factor}

\section{Acknowledgements \\ Not applicable.}

Authors' contributions

EJL prepared the initial manuscript. EMB reviewed and revised the manuscript. RWS contributed the radiographic images and legend text. All authors approved the final manuscript as submitted and agree to be accountable for all aspects of the work.

Funding

Not applicable.

Availability of data and materials

Not applicable.

Ethics approval and consent to participate

This study was reviewed by The Committees for the Protection of Human Subjects (Institutional Review Board) at The Children's Hospital of

Philadelphia and did not meet criteria for human subjects research, therefore the need for ongoing Institutional Review Board was waived.

Consent for publication

Written consent was obtained from the patient and his parent for all aspects of this publication, including photography and clinical imaging.

\section{Competing interests}

The authors declare that they have no competing interests.

\section{Author details}

'Division of Rheumatology, The Children's Hospital of Philadelphia, 3401 Civic Center Blvd, Philadelphia, PA 19104, USA. ²Department of Radiology, The Children's Hospital of Philadelphia, Philadelphia, PA, USA. ${ }^{3}$ Perelman School of Medicine of the University of Pennsylvania, Philadelphia, PA, USA. 
Received: 9 January 2020 Accepted: 3 June 2020

Published online: 09 June 2020

\section{References}

1. Ma NS, Thompson C, Weston S. Brief report: scurvy as a manifestation of food selectivity in children with autism. J Autism Dev Disord. 2016;46(4): 1464-70.

2. Mandl J, Szarka A, Bánhegyi G. Vitamin C: update on physiology and pharmacology. Br J Pharmacol. 2009;157(7):1097-110.

3. Kinlin LM, Blanchard AC, Silver S, Morris SK. Scurvy as a mimicker of osteomyelitis in a child with autism spectrum disorder. Int J Infect Dis. 2018; 69:99-102.

4. Harknett KM, Hussain SK, Rogers MK, Patel NC. Scurvy mimicking osteomyelitis: case report and review of the literature. Clin Pediatr (Phila). 2014:53(10):995-9.

5. Gulko E, Collins LK, Murphy RC, Thornhill BA, Taragin BH. MRI findings in pediatric patients with scurvy. Skelet Radiol. 2015;44(2):291-7.

6. Agathocleous M, Meacham CE, Burgess RJ, Piskounova E, Zhao Z, Crane GM et al. Ascorbate regulates haematopoietic stem cell function and leukaemogenesis. Nature. 2017:549(7673):476-81.

7. Passage E, Norreel JC, Noack-Fraissignes P, Sanguedolce V, Pizant J, Thirion $X$, et al. Ascorbic acid treatment corrects the phenotype of a mouse model of Charcot-Marie-tooth disease. Nat Med. 2004;10(4):396-401.

8. Kondo Y, Inai $Y$, Sato $Y$, Handa S, Kubo S, Shimokado K, et al. Senescence marker protein 30 functions as gluconolactonase in L-ascorbic acid biosynthesis, and its knockout mice are prone to scurvy. Proc Natl Acad Sci U S A. 2006;103(15):5723-8

9. Schleicher RL, Carroll MD, Ford ES, Lacher DA. Serum vitamin C and the prevalence of vitamin C deficiency in the United States: 2003-2004 National Health and nutrition examination survey (NHANES). Am J Clin Nutr. 2009; 90(5):1252-63.

10. Golriz F, Donnelly LF, Devaraj S, Krishnamurthy R. Modern American scurvy experience with vitamin C deficiency at a large children's hospital. Pediatr Radiol. 2017:47(2):214-20

11. Peixoto MJ, Nunes P, Melo R, Timoteo S. Scurvy in Anorexia Nervosa: a case report. Int J Clin Neurosci Mental Health. 2018;5(9).

12. Gongidi $P$, Johnson C, Dinan D. Scurvy in an autistic child: MRI findings. Pediatr Radiol. 2013;43(10):1396-9.

13. Fain O. Musculoskeletal manifestations of scurvy. Joint Bone Spine. 2005; 72(2):124-8.

14. Aghajanian $\mathrm{P}$, Hall $\mathrm{S}$, Wongworawat MD, Mohan $\mathrm{S}$. The roles and mechanisms of actions of vitamin $\mathrm{C}$ in bone: new developments. J Bone Miner Res. 2015;30(11):1945-55.

15. Papadaki M, Rinotas V, Violitzi F, Thireou T, Panayotou G, Samiotaki M, et al. New insights for RANKL as a Proinflammatory modulator in modeled inflammatory arthritis. Front Immunol. 2019;10:97.

\section{Publisher's Note}

Springer Nature remains neutral with regard to jurisdictional claims in published maps and institutional affiliations.

Ready to submit your research? Choose BMC and benefit from:

- fast, convenient online submission

- thorough peer review by experienced researchers in your field

- rapid publication on acceptance

- support for research data, including large and complex data types

- gold Open Access which fosters wider collaboration and increased citations

- maximum visibility for your research: over $100 \mathrm{M}$ website views per year

At $\mathrm{BMC}$, research is always in progress.

Learn more biomedcentral.com/submissions 